Zwikker, H., Bemt, B. van den, Ende, C. van den, Lankveld, W. van, Broeder, A. den, Hoogen, F. van den, Mosselaar, B. van de, Dulmen, S. van. Development and content of a group-based intervention to improve medication adherence in non-adherent patients with rheumatoid arthritis. Patient Education and Counseling: 2012, 89(1), 143-151

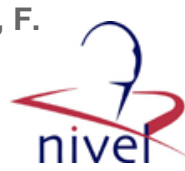

\begin{tabular}{|l|l|}
$\begin{array}{l}\text { Postprint } \\
\text { Version }\end{array}$ & 1.0 \\
\hline Journal website & $\underline{\text { http://www.pec-journal.com/article/S0738-3991(12)00296-0/abstract }}$ \\
\hline Pubmed link & $\underline{\text { http://www.ncbi.nlm.nih.gov/pubmed/22878029 }}$ \\
\hline DOI & $10.1016 /$ j.pec.2012.07.007
\end{tabular}

This is a NIVEL certified Post Print, more info at http://www.nivel.eu

\title{
Development and content of a group-based intervention to improve medication adherence in non-adherent patients with rheumatoid arthritis
}

\author{
HANNEKE ZWIKKER ${ }^{\mathrm{A}}$, BART VAN DEN BEMT ${ }^{\mathrm{A}}$, CORNELIA VAN DEN ENDE ${ }^{\mathrm{A}}$, WIM VAN \\ LANKVELD $^{\mathrm{A}}$, ALFONS DEN BROEDER ${ }^{\mathrm{A}}$, FRANK VAN DEN HOOGEN ${ }^{\mathrm{A}}$, BIRGIT VAN DE \\ MOSSELAAR $^{A}$, SANDRA VAN DULMEN ${ }^{\text {BCD }}$ \\ ${ }^{a}$ Department of Rheumatology and Pharmacy, Sint Maartenskliniek, Nijmegen, The \\ Netherlands

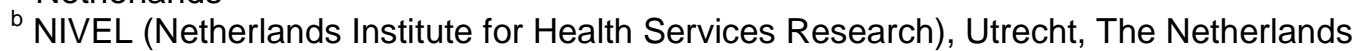 \\ ${ }^{\mathrm{c}}$ Department of Primary and Community Care, Radboud University Nijmegen Medical \\ Centre, Nijmegen, The Netherlands \\ ${ }^{d}$ Department of Health Science, Buskerud University College, Drammen, Norway
}

\begin{abstract}
Objective: To describe the systematic development and content of a short intervention to improve medication adherence to disease-modifying antirheumatic drugs in non-adherent patients with rheumatoid arthritis (RA).

Methods: The intervention mapping (IM) framework was used to develop the intervention. The following IM steps were conducted: (1) a needs assessment; (2) formulation of specific intervention objectives; (3) inventory of methods and techniques needed to design the intervention and (4) production and piloting of the intervention.

Results: The intervention (consisting of two group sessions led by a pharmacist, a homework assignment, and a follow-up call) aims to improve the balance between necessity and concern beliefs about medication, and to resolve practical barriers in medication taking. The central communication method used is motivational interviewing.

Conclusion: By applying the IM framework, we were able to create a feasible, time-efficient and promising intervention to improve medication adherence in non-adherent RA patients. Intervention effects are currently being assessed in a randomized controlled trial.

Practice implications: This paper could serve as a guideline for other health care professionals when developing similar interventions. If the RCT demonstrates sufficient effectiveness of this intervention in reducing medication non-
\end{abstract}


Zwikker, H., Bemt, B. van den, Ende, C. van den, Lankveld, W. van, Broeder, A. den, Hoogen, F. van den, Mosselaar, B. van de, Dulmen, S. van. Development and content of a group-based intervention to improve medication adherence in non-adherent patients with rheumatoid arthritis. Patient Education and Counseling: 2012, 89(1), 143-151

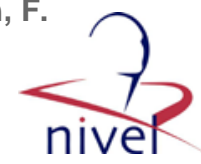

adherence in RA patients, the intervention could be embedded in clinical practice.

\section{INTRODUCTION}

Adherence to disease-modifying anti-rheumatic drugs (DMARDs) in patients with rheumatoid arthritis (RA) (a chronic polyarthritis often leading to joint damage) is not optimal and ranges from $58 \%$ to $82 \%{ }^{[1]}{ }^{[2]}$ and ${ }^{[3]}$. Taking DMARDs as prescribed can, however, limit or prevent disease activity, pain, joint and radiological damage, and can improve long term functional outcome in RA patients. DMARDs can also cause side effects, such as gastro-intestinal complaints, low white blood counts, and abnormal liver function tests ${ }^{[4]}$. These side effects, amongst other factors, may contribute to non-adherence to DMARDs, which can have serious consequences. Non-adherence reduces treatment efficacy, which in turn can result in unnecessary disease activity, joint/radiological damage, and loss of function ${ }^{[5]},{ }^{[6]}$ and ${ }^{[7]}$. Moreover, the annual costs of non-adherence for all conditions in the USA have been estimated to be $\$ 100$ billion ${ }^{[8]}$. In view of the negative implications of medication non-adherence, this behavior thus should be addressed.

To date, evidence supporting the effectiveness of health interventions to improve medication adherence in RA and other chronic illnesses remains inconclusive ${ }^{[9]}$ and

${ }^{[10]}$. The effectiveness of a medication adherence intervention in RA has been assessed in three studies ${ }^{[11]},{ }^{[12]}$ and ${ }^{[13]}$. Only one of these studies demonstrated a slight improvement in adherence to D-penicillamine after a patient education program ${ }^{[12]}$. This program, however, was intensive (51 individuals, $6 \times 30 \mathrm{~min}$ ) and time-inefficient, as it was not group-based and it was intended for both adherent and non-adherent patients. Moreover, all three studies lacked a description of the development process and grounding of these interventions in empirical evidence, theory, and practice perspectives. Consequently, internal and external validity of these interventions is insufficiently guaranteed.

The aim of the present paper is to transparently describe the systematic development and content of a short, time-efficient intervention to improve medication adherence to DMARDs in non-adherent RA-patients. The intervention consists of two motivational interviewing-guided ${ }^{[14]}$ group sessions led by a pharmacist, aimed at improving the individual patient's balance between necessity and concern beliefs about medication and at resolving practical barriers in medication taking. We used the intervention mapping framework ${ }^{[15]}$ (a common framework not yet used in RA interventions) to systematically apply theories, empirical evidence, and practice perspectives in the development of the intervention.

\section{MeTHODS}

Intervention mapping (IM) comprises six steps, each leading to a product that guides the next step. ${ }^{\text {Fig. } 1}$ (derived from Brug and colleagues ${ }^{[16]}$ ) depicts these steps and their operationalization during our development process.

\section{[FIGURE 1]}

The IM framework was chosen because it (1) enhances the formulation of intervention objectives based on empirical evidence and/or theory; (2) covers all the important objectives; (3) links final materials and activities to theory; and (4) ensures 
Zwikker, H., Bemt, B. van den, Ende, C. van den, Lankveld, W. van, Broeder, A. den, Hoogen, F. van den, Mosselaar, B. van de, Dulmen, S. van. Development and content of a group-based intervention to improve medication adherence in non-adherent patients with rheumatoid arthritis. Patient Education and Counseling: 2012, 89(1), 143-151

the intervention is compatible with the target population ${ }^{[17]}$. IM has already been used successfully in, for example, asthma management, HIV prevention, and sun protection $^{[18]}$.

In the present study, the IM steps were conducted by members of a multidisciplinary task group, consisting of pharmacists, researchers, psychologists, rheumatologists, experts on motivational interviewing, and RA patients. Two task group members $[\mathrm{WvL}, \mathrm{BvdM}]$ were responsible for the daily coordination; final decisions regarding the development process and output of the IM steps were reached through discussion in task group meetings.

This section describes how each IM step was operationalized.

\subsection{Needs assessment - analysis of determinants}

Possible targets of the intervention were identified by carrying out a literature study, a cross-sectional study, and a focus group study about medication non-adherence and possible determinants among RA patients.

The literature study ${ }^{[19]}$ was based on publications about determinants of medication non-adherence in RA that were retrieved from Pubmed, PsychInfo, Embase and Cinahl [BvdB/BvdM]. The search strategy included all possible search terms (MeSH and text word) for rheumatoid arthritis, medication non-adherence, compliance, and persistence.

For the cross-sectional study [BvdB] ${ }^{[20]}, 228$ consecutive RA patients on DMARD therapy treated in the St. Maartenskliniek (a clinic specialized in rheumatology, rehabilitation and orthopedic surgery) completed questionnaires to examine the prevalence and possible determinants of non-adherence, including demographics, coping, beliefs about medication, satisfaction about medicine information, and physical functioning. Non-adherence was measured with the Compliance Questionnaire Rheumatology $\left(\mathrm{CQR}^{[21]}\right)$ and the Medication Adherence Report Scale (MARS ${ }^{[22]}$ ).

To gain in-depth insight into possible determinants of non-adherence, two patient focus groups led by two psychologists [WvL/BvdM] were organized to discuss necessity and concern beliefs about medication, the need for education, experienced social support, and practical barriers as perceived by RA patients. The focus groups (seven patients per group) consisted of a non-selective sample of fourteen nonadherent RA patients (selected according to CQR data of the cross-sectional study, with non-adherence being defined as taking $<80 \%$ of prescribed medications).

\subsection{Intervention objectives}

The results of the needs assessment were discussed during task group meetings.

Subsequently, modifiable determinants of non-adherence relevant to our target group (adult, non-adherent RA patients taking DMARDs) were selected as targets for the intervention. To achieve the overall aim of the intervention (improving participants' medication adherence), specific intervention objectives (Section ${ }^{3.2}$ ) were formulated for each determinant to identify exactly what needed to change during the intervention.

\subsection{Health behavior change methods and techniques}

Literature about established communication - and health behavior (change) models, - methods and - theories was studied [GB], to identify appropriate methods and 
Zwikker, H., Bemt, B. van den, Ende, C. van den, Lankveld, W. van, Broeder, A. den, Hoogen, F. van den, Mosselaar, B. van de, Dulmen, S. van. Development and content of a group-based intervention to improve medication adherence in non-adherent patients with rheumatoid arthritis. Patient Education and Counseling: 2012, 89(1), 143-151

techniques in accordance with the specific intervention objectives. Based on this literature study, the task group selected health behavior change methods and techniques to be used during the intervention.

\subsection{Intervention content and pilot}

The intervention objectives and selected methods and techniques were combined in a single plan [GB], namely the intervention protocol. Draft versions of this intervention protocol were discussed during task group meetings, resulting in the final version of the intervention protocol. Based on this final intervention protocol, materials were developed, such as a participant workbook with homework assignments (Section ${ }^{3.4}$ ).

The feasibility of the intervention (consisting of two consecutive group sessions, see Section ${ }^{3.4}$ ) was examined by piloting the intervention twice. A non-selective sample of twelve adult, non-adherent RA patients (based on CQR data of the cross-sectional study) was recruited for the pilot. The pilot was attended by an expert panel, consisting of two psychologists, and a patient panel (independent advisory board comprising two RA patients familiar with scientific research). A global checklist and a patient satisfaction questionnaire were developed [BvdM] to assess the communication style of the intervention, transparency of information, and satisfaction about general intervention characteristics, such as session duration and group size.

\subsection{Implementation and evaluation of the intervention}

Implementation of the intervention was facilitated by (1) the pilot of the intervention (Section ${ }^{2.4}$ ) and (2) the task group participation of rheumatologists and pharmacists responsible for carrying out the intervention in clinical practice. Furthermore, a practical workbook for use during the intervention was written for these rheumatologists and pharmacists (Section ${ }^{3.4}$ ). To check treatment integrity, audiotaped intervention sessions will be analyzed.

To objectify intervention effects on treatment outcomes, a research proposal was drafted for a randomized controlled trial (Section ${ }^{3.5}$ ).

\section{RESULTS}

\subsection{Needs assessment - analysis of determinants}

\subsubsection{Literature study}

The literature study into the empirical determinants of medication non-adherence in RA revealed that non-adherence is a multidimensional phenomenon, with determinants not consistently associated with non-adherence across studies ${ }^{[19]}$.

Although regimen complexity, a poor patient-provider relationship, costs of drugs, lack of social support, a low level of self efficacy, and beliefs about medication (including perceived (side) effects of medication) tend to be associated with medication non-adherence, these associations are often weak.

Recently, determinants of medication non-adherence have been conceptualized as 'unintentional' or 'intentional' factors of non-adherence ${ }^{[19]}$. Unintentional nonadherence reflects a person's lack of ability and skills to take medicines, including forgetting or poor manual dexterity ${ }^{[23]}$, while intentional non-adherence is driven by 
Zwikker, H., Bemt, B. van den, Ende, C. van den, Lankveld, W. van, Broeder, A. den, Hoogen, F. van den, Mosselaar, B. van de, Dulmen, S. van. Development and content of a group-based intervention to improve medication adherence in non-adherent patients with rheumatoid arthritis. Patient Education and Counseling: 2012, 89(1), 143-151

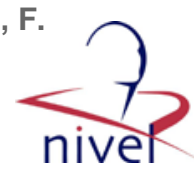

a decision not to take medicines as prescribed. It is assumed that adherence decisions are influenced by a cost-benefit assessment in which personal beliefs (assumptions and convictions that are believed to be true by an individual) about the necessity of the medication for maintaining or improving health are balanced against concerns about the potential adverse effects of taking the medication ${ }^{[24]}$. It should be noted, however, that this cost-benefit assessment may be implicit rather than explicit and unconscious rather than conscious ${ }^{[25]}$ and ${ }^{[26]}$. Nevertheless, targeting intentional non-adherence (beliefs about medication) as well as unintentional non-adherence (e.g., practical barriers) might improve medication adherence ${ }^{[27]}$ and ${ }^{[28]}$.

\subsubsection{Cross-sectional study}

In the cross-sectional study, an association between beliefs about medication and non-adherence was confirmed for necessity beliefs about medication ${ }^{[20]}$. Adherent patients had higher mean necessity scores than non-adherent patients (20.3 versus $19.1 ; p=0.02)$. Moreover, patients with recent onset RA were more adherent than patients with a longer RA duration (76\% and 62\%, respectively; $p=0.05$ ).

Furthermore, adherent patients (according to the CQR) reported fewer adverse medication effects than non-adherent patients.

Although $>90 \%$ of patients had one or more concerns about their medication, concern beliefs about medication were not associated with non-adherence. This also applied to satisfaction about information, coping, physical functioning, and demographics.

\subsubsection{Focus groups}

The focus groups revealed that all participants had necessity beliefs and concern beliefs about medication. Although the nature of beliefs varied highly between individuals, almost all patients perceived medications as a 'necessary evil' and as 'chemical junk'. Almost half of the participants appeared to experiment with their medication to find a balance between taking it (because of the inevitable necessity) and not taking it (because of (possible) adverse effects).

Participants reported that they preferred receiving oral information about RA and medications from peers and rheumatologists rather than receiving written information. Additionally, participants stressed the importance of practical support from their spouses in overcoming practical barriers such as forgetfulness, difficulties in opening pill strips and bottles, difficulties with cooling medication on holidays, and difficulties with injecting medicines.

\subsection{Intervention objectives}

Based on the needs assessment, the task group selected determinants as targets of the intervention. These determinants are shown in ${ }^{\text {Table } 1}$, along with their corresponding intervention objectives.

\section{[TABLE 1]}

The task group chose only to target modifiable determinants or resolvable practical barriers in medication taking, and therefore non-adherence determinants like a poor patient-provider relationship or costs of drugs were not selected as intervention 
Zwikker, H., Bemt, B. van den, Ende, C. van den, Lankveld, W. van, Broeder, A. den, Hoogen, F. van den, Mosselaar, B. van de, Dulmen, S. van. Development and content of a group-based intervention to improve medication adherence in non-adherent patients with rheumatoid arthritis. Patient Education and Counseling: 2012, 89(1), 143-151

targets. However, the task group found beliefs about medication to be a promising intervention target, since most published interventions failed to systematically target such beliefs and since beliefs about medication played a significant role in all three sub-studies of our needs assessment. Furthermore, since our focus groups revealed that most RA patients experience practical barriers in medication taking, several task group members suggested that effectiveness of adherence interventions could be increased by targeting both intentional non-adherence (i.e., beliefs about medication) and unintentional non-adherence (i.e., practical barriers).

To accomplish the central intervention objectives, three prerequisites (defined as 'enabling determinants') should be met. Two out of three prerequisites were derived from the needs assessment by the task group: (1) 'social influence' had to be incorporated into the intervention, because our focus groups revealed that RA patients prefer receiving oral information about RA and medications from peers and rheumatologists rather than receiving written information; (2) self-efficacy in taking medication should be enhanced. According to the literature study, poor self-efficacy correlates with non-adherence, and the task group therefore assumed that enhancing self-efficacy may help patients to overcome their practical barriers. The last prerequisite, which is unrelated to the outcome of the needs assessment ('RA patients should have adequate knowledge about RA, RA medication, and non-adherence') was suggested by the task group because they felt that adequate medication knowledge in patients is important in changing beliefs about medication ${ }^{[16]}$. The task group decided to focus the intervention on adults (as treatment of children with RA in the St. Maartenskliniek was scarce at the time of intervention development) and on patients with a disease duration of longer than one year (as we assumed medication-taking behavior would be more stable). The intervention was not further tailored to subgroups, as the needs assessment found that demographic factors were no strong predictors of non-adherence.

\subsection{Health behavior change methods and techniques}

To explain the association between beliefs about medication, practical barriers, and medication non-adherence to patients (knowledge objective, see Table ${ }^{1}$ ), easy-tounderstand patient education was needed. We therefore developed a simple health behavior model ( ${ }^{\text {Fig. } 2}$ ), based on elements of the Health Belief Model ${ }^{\text {[29] }}$ (used in the field of non-adherence ${ }^{[24]}$ ), and the Integrated Change Model (the latest version of the widely used ASE model (Attitude-Social Influence-Self-efficacy model) in the Netherlands ${ }^{[30]}$ ).

\section{[FIGURE 2]}

This simple model was also used as a visual tool and as a stepping stone during the intervention (details of use are described in Section ${ }^{3.4}$ and in ${ }^{\text {Table } 2}$ ).

\section{[TABLE 2]}

The central communication style of the intervention had to comply with two requirements, derived from the central intervention objectives of 'beliefs' and 'practical barriers': 
Zwikker, H., Bemt, B. van den, Ende, C. van den, Lankveld, W. van, Broeder, A. den, Hoogen, F. van den, Mosselaar, B. van de, Dulmen, S. van. Development and content of a group-based intervention to improve medication adherence in non-adherent patients with rheumatoid arthritis. Patient Education and Counseling: 2012, 89(1), 143-151

1. the communication style should be open and non-judgmental. As it could be uncomfortable for patients to talk about their non-adherence, personal beliefs about medication, and their own practical barriers, patients should feel safe to express their thoughts and feelings;

2. the communication style should be suitable for exploring individual necessity and concern beliefs about medication and individual ambivalence regarding the pros and cons of medication. According to our needs assessment, beliefs vary highly among individuals, and people are more likely to elaborate on information when messages are personalized ${ }^{[16]}$.

The task group decided that motivational interviewing (MI) could be a useful communication style to explore patients' individual ambivalence and the balance between necessity and concern beliefs about medication. MI is a non-judgmental, patient-centered approach that facilitates behavior change by helping patients to explore and resolve their individual ambivalence about behavior change ${ }^{[14]}$. MI has proven to be successful in different individual and group behavioral settings ${ }^{[31]}$, ${ }^{[32]}$ and ${ }^{[33]}$.

Expressing empathy, developing discrepancy (e.g., in the balance of necessity and concern beliefs), avoiding argumentation and confrontation, rolling with resistance, and supporting self-efficacy are underlying MI principles ${ }^{[14]}$. These principles can be translated into the following MI techniques: (1) reflective listening; (2) expressing acceptance and affirmation; (3) monitoring patients' readiness to change beliefs and behavior (ensuring that resistance is not generated by pushing patients to change beliefs or behavior); (4) affirming the patient's freedom of choice and selfdetermination regarding changing beliefs and behavior; and (5) giving the patient a more active role than the intervention leader ${ }^{[14]}$. To master these techniques, our intervention leaders followed a course in MI at a renowned MI center in the Netherlands.

The task group decided on the following intervention format: two MI-guided group sessions (1.5 h each, 5-7 RA patients (a manageable group size) led by a pharmacist, an individual homework assignment between the two sessions (therefore sessions took place one week apart), and a follow-up call by the pharmacist eight weeks after the last group meeting.

The group format was used to accomplish the intervention objectives of 'social influence/modeling' (whereby modeling is a technique in itself) and 'self-efficacy'. People can enhance self-efficacy, for example, by observing and listening to others according to Bandura's social cognitive theory ${ }^{[34]}$ ). The number of sessions was set at two to keep the intervention short and time-efficient, to enable discussion about the outcomes of the individual homework assignment, and to repeat shared information from the first session, as repeating messages increases the likelihood of information being recalled ${ }^{[35]}$. The aim of the follow-up call also was recall of information. As trustworthy messengers increase the chance of behavior change and adopting messages ${ }^{[36]}$, the task group decided that a pharmacist should lead the interventions and that a rheumatologist should provide education about RA and RA medications (see knowledge objectives in Section ${ }^{3.2}$ ) during the second session. 
Zwikker, H., Bemt, B. van den, Ende, C. van den, Lankveld, W. van, Broeder, A. den, Hoogen, F. van den, Mosselaar, B. van de, Dulmen, S. van. Development and content of a group-based intervention to improve medication adherence in non-adherent patients with rheumatoid arthritis. Patient Education and Counseling: 2012, 89(1), 143-151

All developed intervention materials are described in Section ${ }^{3.4}$.

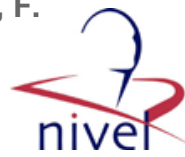

\subsection{Program development and production}

All separate intervention mapping steps were combined in the intervention protocol [37]. Table 2 summarizes the protocol content and shows the link between this content and determinants, intervention objectives, methods, and techniques.

In sum, using MI techniques, a pharmacist invited participants to reflect on their own concern and necessity beliefs and on practical barriers regarding DMARD use, to share those beliefs and barriers with their peers in a non-threatening environment and, eventually, to change unrealistic beliefs and to resolve practical barriers. For example, one participant believed that her medication was poisoning her body. The intervention leader, amongst others, acknowledged that DMARDs do have side effects, but he also emphasized that not taking DMARDs as prescribed would do even more harm to her body. The other participants' opinions about this information were subsequently discussed and, in this way, the participant was invited to change her point of view about DMARDs.

All intervention materials and their function are shown in Table 3.

\section{[TABLE 3]}

\subsubsection{Pilot of intervention}

During the pilot, the expert panel and the patient panel reported that they found the provided information easy to understand and that they appreciated the motivational interviewing communication style, as they found it to be open and non-judgmental. Although accuracy of the applied MI techniques was not checked with a validated instrument like MITI ${ }^{[38]}$, the panels observed a consistent application of MI skills during the intervention. Moreover, overall patient satisfaction about the intervention was high (see ${ }^{\text {Table } 4}$ ). Patients thought that the provided information was transparent and understandable, and found the atmosphere to be relaxed.

\section{[TABLEL 4]}

The patients, however, found the number of sessions to be slightly too low. Nonetheless, the number of sessions was not increased as the task group wished to keep the intervention short. The intervention was, however, adapted in response to three concerns expressed by both the expert panel and the patient panel: (1) the intervention leader had to give participants more opportunity to express themselves. As a result, the active role of the participant was emphasized in the intervention leader workbook; (2) at the start of the intervention, the intervention leader should have told participants that it was not compulsory to answer personal questions.

Apparently, this made participants to feel 'unsafe'. Hence, indicating that answering personal questions is not compulsory was explicitly added as action point for the intervention leader in the workbook; (3) the rheumatologist's white coat was considered undesirable, so the workbook was adapted accordingly.

\subsection{Evaluation of the intervention}

The effects of the intervention will be determined in a single-blind, randomized, controlled trial (number in trial register: ${ }^{\text {NCT00968266 }}$ ). 120 eligible, non-adherent RA 
Zwikker, H., Bemt, B. van den, Ende, C. van den, Lankveld, W. van, Broeder, A. den, Hoogen, F. van den, Mosselaar, B. van de, Dulmen, S. van. Development and content of a group-based intervention to improve medication adherence in non-adherent patients with rheumatoid arthritis. Patient Education and Counseling: 2012, 89(1), 143-151

patients (non-adherent defined as taking $<80 \%$ of medication according to the Compliance Questionnaire Rheumatology ${ }^{[21]}$ ) were randomized into the intervention group or control group. The control group received care as usual in the form of a brochure about currently used medication.

The primary outcome of interest is medication adherence, measured by the Compliance Questionnaire Rheumatology ${ }^{[21]}$, the Medication Adherence Report Scale ${ }^{[22]}$ and pharmacy refill rates ${ }^{[39]}$ and ${ }^{[40]}$. The primary parameter of interest is beliefs about medication (measured by the Beliefs about Medicine Questionnaire, $B M Q^{[41]}$ ). Outcomes and parameters are measured at baseline (questionnaires three weeks before start of the experimental and control intervention) and at one week, six months, and one year follow-up after the intervention. The results are expected to be available in 2013.

\section{DISCUSSION AND CONCLUSION}

\subsection{Discussion}

To the best of our knowledge, this is the first study that transparently describes the systematic development and content of a short, time-efficient intervention to improve medication adherence to DMARDs in non-adherent RA patients. The intervention targets the balance between necessity and concern beliefs about medication and tends to resolve practical barriers in medication taking. As medication non-adherence

negatively affects patients' disease activity and quality of life, effective interventions to improve adherence are urgently needed.

The development process of this study had several strengths. Initially, this is the first RA medication adherence intervention in which intervention mapping (IM) has been applied and for which the development process has been thoroughly described. IM structured the development process and enabled systematic use of theory, empirical evidence, and practical perspectives in the development of the intervention. In contrast, most development processes for health interventions are characterized by the ad hoc use of theories and empirical evidence ${ }^{[18]}$, or they are only marginally described.

A second strength of our development process was the multidisciplinarity of the task group, which enabled use of broad knowledge, experiences and visions. Furthermore, sufficient time, staff, and budget were available to allow the task group to thoroughly carry out every step of the IM framework.

A potential limitation of the development process was that it was not as linear as proposed by the IM framework. Parts of step 1 (mapping determinants), step 2 (formulating intervention objectives), and step 3 (collecting health behavior change methods and techniques) were performed in a more parallel rather than sequential manner. However, we do not believe that this parallel approach has affected the quality of our intervention, since designing processes are iterative and recursive in nature ${ }^{[42]}$. Planning models like IM, moreover, are intended to prompt intervention developers to ask themselves the appropriate questions and to make the appropriate decisions ${ }^{[16]}$.

The intervention itself has strong features compared with other motivational interviewing-based interventions for medication non-adherence in chronic diseases such as HIV ${ }^{[43]}$, ${ }^{[44]},{ }^{[45]}$ and ${ }^{[46]}$, glaucoma ${ }^{[47]}$, and asthma ${ }^{[48]}$. In contrast to these interventions, our intervention is short and time-efficient: brief interventions might 
Zwikker, H., Bemt, B. van den, Ende, C. van den, Lankveld, W. van, Broeder, A. den, Hoogen, F. van den, Mosselaar, B. van de, Dulmen, S. van. Development and content of a group-based intervention to improve medication adherence in non-adherent patients with rheumatoid arthritis. Patient Education and Counseling: 2012, 89(1), 143-151

be as effective as intensive treatments ${ }^{[49]}$. Furthermore, and in contrast to other studies, we only targeted non-adherent patients. This not only makes our intervention more time-efficient, but also makes MI-based communication during the intervention more meaningful. Finally, most previously reported interventions target individual patients during several one-to-one meetings, which is more expensive and not necessarily more effective than group-based formats ${ }^{[50]}$ and ${ }^{[51]}$.

However, one could argue that a group format might compromise MI effectiveness as the format might prevent each individuals' specific needs from being met ${ }^{[14]}$. Nonetheless, this thought is not in line with the demonstrated successes of groupbased MI interventions ${ }^{[31]}{ }^{[32]}$ and ${ }^{[33]}$. Moreover, our intervention does address individuals' specific needs, for example through the individual homework assignment and the discussion of individual beliefs and barriers.

Regarding content of our intervention, there is one significant difference with other MI-based interventions for medication non-adherence ${ }^{[43]},{ }^{[44]},{ }^{[45]},{ }^{[46]},{ }^{[47]}$ and ${ }^{[48]}$. Although the latter do address beliefs, knowledge or barriers regarding medication taking, none systematically focus on changing the balance between necessity and concern beliefs about medication. Instead, significant effort is put into mapping participants' motivation for behavior change and into behavioral goal setting. However, we believe that a realistic balance between necessity and concern beliefs about medication is necessary and that barriers should be addressed before focusing on behavior change.

The focus on changing the balance between necessity and concern beliefs (in addition to resolving practical barriers) is a fairly unique feature of our intervention compared to other MI-based and non-MI-based interventions for non-adherence in chronic conditions. Despite the apparent link between beliefs about medication and non-adherence ${ }^{[20]},{ }^{[23]},{ }^{[24]},{ }^{[27]},{ }^{[28]}{ }^{[41]},{ }^{[52]}$ and ${ }^{[53]}$, other interventions fail to (thoroughly) target those beliefs ${ }^{[9]}$.

A potential limitation of the intervention could be the use of a manual during the intervention, as manual-guided MI might be associated with smaller effect sizes ${ }^{[31]}$. This might occur because, for example, the intervention leaders might end a session by drawing up a concrete behavior change plan (as the manual prescribes), regardless of whether patients seemed ready to do so, thereby violating MI itself ${ }^{[31]}$. However, the manual used in our intervention explicitly states that pressuring participants to decide on adherence intentions or to make behavior change plans is not allowed. In fact, acknowledgment of different needs in individual participants is a key feature of our intervention. A major strength of using manuals, moreover, is that they facilitate standardization of the intervention.

\subsection{Conclusion}

By applying the IM framework, the task group was able to create a unique, efficient and promising intervention to improve medication adherence in non-adherent RA patients. In line with other authors ${ }^{[15]}$ and ${ }^{[18]}$, we believe that the IM framework can improve intervention development. Our RCT will indicate whether the intervention has desirable effects on beliefs about medication and non-adherence.

\subsection{Practice implications}

Pharmacists and rheumatologists who performed the intervention found the intervention feasible. Moreover, general patient satisfaction about the intervention 
Zwikker, H., Bemt, B. van den, Ende, C. van den, Lankveld, W. van, Broeder, A. den, Hoogen, F. van den, Mosselaar, B. van de, Dulmen, S. van. Development and content of a group-based intervention to improve medication adherence in non-adherent patients with rheumatoid arthritis. Patient Education and Counseling: 2012, 89(1), 143-151

was high according to the intervention pilot data. Thus, if the RCT demonstrates sufficient effectiveness of this intervention in reducing medication non-adherence in RA patients, the intervention could be embedded in clinical practice.

The content of this paper could serve as guideline for the development of other interventions and could thereby contribute to a meaningful integration of theory, empirical evidence and practice perspectives in interventions.

\section{FINANCIAL SUPPORT}

None.

\section{CONFLICT OF INTEREST}

None.

\section{ACKNOWLEDGEMENTS}

We would like to thank Geert Bouwmans and Rik Bes for their substantial contributions in developing the intervention.

\section{REFERENCES}

[1] Doyle DV, Perrett D, Foster OJ, Ensor M, Scott DL. The long-term use of penicillamine for treating rheumatoid arthritis: is continuous therapy necessary? $\mathrm{Br} \mathrm{J}$ Rheumatol 1993;32:614-7.

[2] Brus H, van de Laar M, Taal E, Rasker J, Wiegman O. Determinants of compliance with medication in patients with rheumatoid arthritis: the importance of self-efficacy expectations. Patient Educ Couns 1999;36:57-64.

[3] Pullar T, Peaker S, Martin MF, Bird HA, Feely MP. The use of a pharmacological indicator to investigate compliance in patients with a poor response to antirheumatic therapy. $\mathrm{Br} \mathrm{J}$ Rheumatol 1988;27:381-4.

[4] Bijlsma JWJ. In: Burmester GR, Da Silva JAP, Faarvang KL, Hachulla E, Mariette X, editors. Eular compendium on rheumatic diseases. first ed., BMJ Publishing Group/European League against Rheumatism; 2009.

[5] Van den Bemt BJF. Optimizing pharmacotherapy in patients with rheumatoid arthritis: an individualized approach. The Netherlands: Radboud University Nijmegen; 2009.

[6] Contreras-Yanez I, Ponce De LS, Cabiedes J, Rull-Gabayet M, Pascual-Ramos V. Inadequate therapy behavior is associated to disease flares in patients with rheumatoid arthritis who have achieved remission with disease-modifying antirheumatic drugs. Am J Med Sci 2010;340:282-90.

[7] Viller F, Guillemin F, Briancon S, Moum T, Suurmeijer T, van den Heuvel W. Compliance to drug treatment of patients with rheumatoid arthritis: a 3 year longitudinal study. J Rheumatol 1999;26:2114-22.

[8] Osterberg L, Blaschke T. Adherence to medication. N Engl J Med 2005; 353:487-97.

[9] Haynes RB, Ackloo E, Sahota N, McDonald HP, Yao X. Interventions for enhancing medication adherence. Cochrane Database Syst Rev 2008; CD000011.

[10] McDonald HP, Garg AX, Haynes RB. Interventions to enhance patient adherence to medication prescriptions: scientific review. J Amer Med Assoc 2002;288:2868-79.

[11] Van den Bemt BJF, den Broeder AA, van den Hoogen FH, Benraad B, Hekster YA, van Riel PL, et al. Making the rheumatologist aware of patients' non-adherence does not improve medication adherence in patients with rheumatoid arthritis. Scand J Rheumatol 2011;40:192-6.

[12] Brus HL, van de Laar MA, Taal E, Rasker JJ, Wiegman O. Effects of patient education on compliance with basic treatment regimens and health in recent onset active rheumatoid arthritis. Ann Rheum Dis 1998;57:146-51. 
Zwikker, H., Bemt, B. van den, Ende, C. van den, Lankveld, W. van, Broeder, A. den, Hoogen, F. van den, Mosselaar, B. van de, Dulmen, S. van. Development and content of a group-based intervention to improve medication adherence in non-adherent patients with rheumatoid arthritis. Patient Education and Counseling: 2012, 89(1), 143-151

[13] Hill J, Bird H, Johnson S. Effect of patient education on adherence to drug treatment for rheumatoid arthritis: a randomised controlled trial. Ann Rheum Dis 2001;60:869-75.

[14] Britt E, Hudson SM, Blampied NM. Motivational interviewing in health settings: a review. Patient Educ Couns 2004;53:147-55.

[15] Bartholomew LK, Parcel GS, Kok G. Intervention mapping: a process for developing theory- and evidence-based health education programs. Health Educ Behav 1998;25:54563.

[16] Brug J, Schaalma H, Kok G, Meertens RM, van der Molen HT. Gezondheidsvoorlichting en gedragsverandering: een planmatige aanpak. Health education and behavior change: a systematic approach Assen: Koninklijke Van Gorcum B.V.; 2003.

[17] Kok G, Schaalma H, Ruiter RA, van Empelen P, Brug J. Intervention mapping: protocol for applying health psychology theory to prevention programmes. J Health Psychol 2004;9:85-98.

[18] Heinen MM, Bartholomew LK, Wensing M, van de Kerkhof $P$, van Achterberg T. Supporting adherence and healthy lifestyles in leg ulcer patients: systematic development of the Lively Legs program for dermatology outpatient clinics. Patient Educ Couns 2006;61:279-91.

[19] Van den Bemt BJF, Zwikker HE, van den Ende CHM. Medication adherence in patients with rheumatoid arthritis: a critical appraisal of the existing literature. Expert Rev Clin Immunol 2012;8:337-51.

[20] Van den Bemt BJF, van den Hoogen FH, Benraad B, Hekster YA, van Riel PL, van Lankveld $W$. Adherence rates and associations with nonadherence in patients with rheumatoid arthritis using disease modifying antirheumatic drugs. J Rheumatol 2009;36:2164-70.

[21] De Klerk E, van der Heijde D, Landewe R, van der Tempel H, van der Linden S. The compliance-questionnaire-rheumatology compared with electronic medication event monitoring: a validation study. J Rheumatol 2003;30: 2469-75.

[22] Cohen JL, Mann DM, Wisnivesky JP, Home R, Leventhal H, Musumeci-Szabo TJ, et al. Assessing the validity of self-reported medication adherence among inner-city asthmatic adults: the Medication Adherence Report Scale for Asthma. Ann Allergy Asthma Immunol 2009;103:325-31.

[23] Clifford S, Barber N, Horne R. Understanding different beliefs held by adherers, unintentional nonadherers, and intentional nonadherers: application of the NecessityConcerns Framework. J Psychosom Res 2008;64:41-6.

[24] Horne R, Weinman J. Patients' beliefs about prescribed medicines and their role in adherence to treatment in chronic physical illness. J Psychosom Res 1999;47:555-67.

[25] Dijksterhuis A. Het slimme onbewuste: denken met gevoel. Smart unawareness: thinking by emotion Amsterdam: Bert Bakker; 2007.

[26] Lee D. Neural basis of quasi-rational decision making. Curr Opin Neurobiol 2006;16:191-8.

[27] Clifford S, Barber N, Elliott R, Hartley E, Horne R. Patient-centred advice is effective in improving adherence to medicines. Pharm World Sci 2006;28:165-70.

[28] Elliott RA. Poor adherence to medication in adults with rheumatoid arthritis: reasons and solutions. Dis Manag Health Outcome 2008;13-29.

[29] Rosenstock IM, Strecher VJ, Becker MH. Social learning theory and the health belief model. Health Educ Q 1988;15:175-83.

[30] Vries H, Mesters I, van de Steeg H, Honing C. The general public' s information needs and perceptions regarding hereditary cancer: an application of the integrated change model. Patient Educ Couns 2005;56:154-65.

[31] Hettema J, Steele J, Miller WR. Motivational interviewing. Annu Rev Clin Psychol 2005;1:91-111.

[32] Oei TP, Raylu N, Casey LM. Effectiveness of group and individual formats of a combined motivational interviewing and cognitive behavioral treatment program for problem gambling: a randomized controlled trial. Behav Cogn Psychother 2010;38:233-8. 
Zwikker, H., Bemt, B. van den, Ende, C. van den, Lankveld, W. van, Broeder, A. den, Hoogen, F. van den, Mosselaar, B. van de, Dulmen, S. van. Development and content of a group-based intervention to improve medication adherence in non-adherent patients with rheumatoid arthritis. Patient Education and Counseling: 2012, 89(1), 143-151

[33] Michael KD, Curtin L, Kirkley DE, Jones DL, Harris RJ. Group-based motivational interviewing for alcohol use among college students: an exploratory study. Prof PsycholRes Pr 2006;37:629-34.

[34] Bandura A. Social foundations of thought and action: a social cognitive theory. Englewood Cliffs, NJ: Prentice-Hall; 1986.

[35] Heath R, Bryant J. Cognitive involvement theory: elaboration likelihood model. Human communication theory and research. Mahwah, NJ: Lawrence Earlbaum Ass.; 2000. p. 196201.

[36] Eagly AH, Chaiken S. The psychology of attitudes. Fort Worth: Harcout Brace Jovanovich; 1993.

[37] Sint Maartenskliniek. Interventieprotocol therapietrouw aan medicatie: bespreken van opvattingen over medicatie en wegnemen van praktische barrières bij therapieontrouwe patiënten met Reumatoïde Artritis. Intervention protocol medication adherence: discussing beliefs about medication with and resolving practical barriers in non-adherent patients with rheumatoid arthritis Sint Maartenskliniek: Nijmegen; 2009.

[38] Moyers TB, Martin T, Manuel JK, Miller WR. The Motivational Interviewing Treatment Integrity (MITI) code. New Mexico: University of New Mexico (Center on Alcoholism, Substance Abuse and Addictions); 2003.

[39] Christensen DB, Williams B, Goldberg HI, Martin DP, Engelberg R, LoGerfo JP. Assessing compliance to antihypertensive medications using computer-based pharmacy records. Med Care 1997;35:1164-70.

[40] Lau HS, de Boer A, Beuning KS, Porsius A. Validation of pharmacy records in drug exposure assessment. J Clin Epidemiol 1997;50:619-25.

[41] Horne R, Weinman J, Hankins M. The Beliefs about Medicines Questionnaire: the development and evaluation of a new method for assessing the cognitive representation of medication. Psychol Health 1999;1-24.

[42] Verschuren $\mathrm{P}$, Doorewaard H. Het ontwerpen van een onderzoek. Designing research Utrecht: Lemma BV; 2004.

[43] Dilorio C, McCarty F, Resnicow K, McDonnell Holstad M, Soet J, Yeager K, et al. Using motivational interviewing to promote adherence to antiretroviral medications: a randomized controlled study. AIDS Care 2008;20:273-83.

[44] Dilorio C, Resnicow K, McDonnell M, Soet J, McCarty F, Yeager K. Using motivational interviewing to promote adherence to antiretroviral medications: a pilot study. J Assoc Nurses AIDS Care 2003;14:52-62.

[45] McDonnell Holstad M, Dilorio C, Kelley ME, Resnicow K, Sharma S. Goup motivational interviewing to promote adherence to antiretroviral medications and risk reduction behaviors in HIV infected women. AIDS Behav 2011;15:885-96.

[46] Krummenachter I, Cavassini M, Bugnon O, Schneider MP. An interdisciplinary HIVadherence program combining motivational interviewing and electronic antiretroviral drug monitoring. AIDS Care 2011;23:550-61.

[47] Cook PF, Bremer RW, Ayala AJ, Kahook MY. Feasibility of motivational interviewing delivered by a glaucoma educator to improve medication adherence. Clin Ophthalmol 2010;4:1091-101.

[48] Riekert KA, Borrelli B, Bilderback A, Rand CS. The development of a motivational interviewing intervention to promote medication adherence among inner-city, AfricanAmerican adolescents with asthma. Patient Educ Couns 2011;82:117-22.

[49] Dunn C, Deroo L, Rivara FP. The use of brief interventions adapted from motivational interviewing across behavioral domains: a systematic review. Addiction 2001;96:1725-42.

[50] Lamb SE, Lall R, Hansen Z, Castelnuovo E, Withers EJ, Nichols V, et al. A multicentred randomised controlled trial of a primary care-based cognitive behavioural programme for low back pain. The Back Skills Training (BeST) trial. Health Technol Assess 2010;14:1281.

[51] Dickson K, Marshall M, Boyle J, McCartney E, O' Hare A, Forbes J. Cost analysis of direct versus indirect and individual versus group modes of manualbased speech-andlanguage therapy for primary school-age children with primary language impairment. Int $\mathrm{J}$ Lang Commun Disord 2009;44:369-81. 
Zwikker, H., Bemt, B. van den, Ende, C. van den, Lankveld, W. van, Broeder, A. den, Hoogen, F. van den, Mosselaar, B. van de, Dulmen, S. van. Development and content of a group-based intervention to improve medication adherence in non-adherent patients with rheumatoid arthritis. Patient Education and Counseling: 2012, 89(1), 143-151

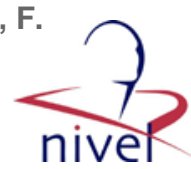

[52] Menckeberg TT, Bouvy ML, Bracke M, Kaptein AA, Leufkens HG, Raaijmakers JA, et al. Beliefs about medicines predict refill adherence to inhaled corticosteroids. J Psychosom Res 2008;64:47-54.

[53] Neame R, Hammond A. Beliefs about medications: a questionnaire survey of people with rheumatoid arthritis. Rheumatology 2005;44:762-7.

\section{TABLES AND FIGURES}

Fig. 1. Model of intervention mapping used for intervention development

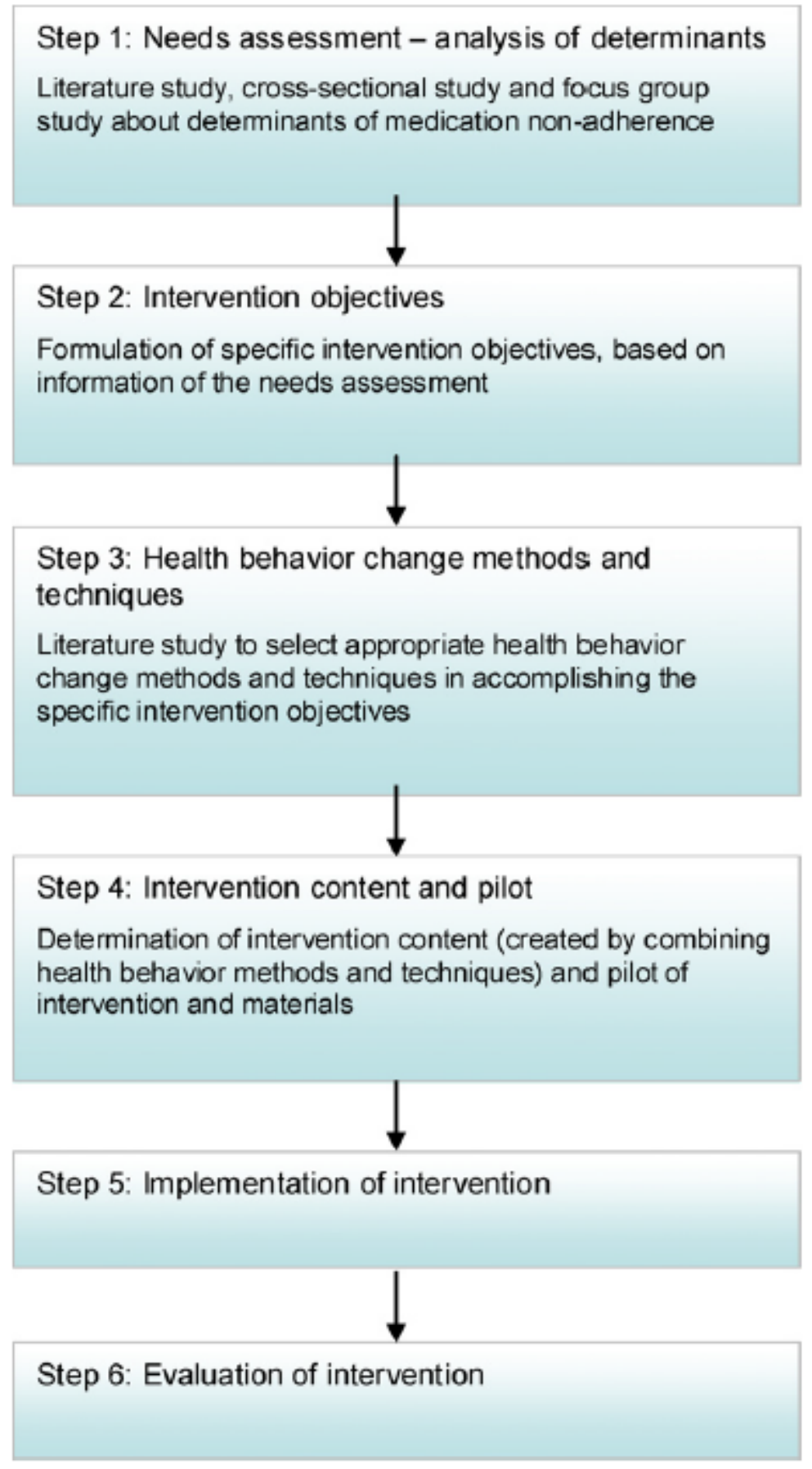


Zwikker, H., Bemt, B. van den, Ende, C. van den, Lankveld, W. van, Broeder, A. den, Hoogen, F. van den, Mosselaar, B. van de, Dulmen, S. van. Development and content of a group-based intervention to improve medication adherence in non-adherent patients with rheumatoid arthritis. Patient Education and Counseling: 2012, 89(1), 143-151

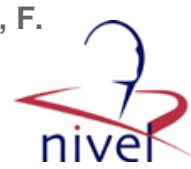

Table 1

Determinants and specific intervention objectives.

\begin{tabular}{|c|c|}
\hline & After the intervention, participants ... \\
\hline \multicolumn{2}{|l|}{ Central determinants } \\
\hline Intentional non-adherence: & .... have an improved balance between necessity and concern beliefs. That is, participants \\
\hline beliefs about medication & have stronger necessity beliefs about medication and less unrealistic concern beliefs about medication \\
\hline $\begin{array}{l}\text { Unintentional non-adherence: } \\
\text { practical barriers }\end{array}$ & $\checkmark$... are able to overcome their own practical barriers in using medication \\
\hline \multicolumn{2}{|l|}{ Enabling determinants } \\
\hline \multirow[t]{2}{*}{ Knowledge } & $\checkmark$... have adequate knowledge about RA and RA-medications \\
\hline & $\sim$... understand that beliefs about medication and practical barriers contribute to non-adherent behavior \\
\hline Social influence: modeling & $\begin{array}{l}\text { and have a clear picture of their own beliefs about medication and practical barriers, by listening } \\
\text { and to their 'peer participants' }\end{array}$ \\
\hline Self-efficacy & $\begin{array}{l}\text {... discussed and obtained skills to overcome their own practical barriers in using medication, } \\
\text { so self efficacy is enhanced }\end{array}$ \\
\hline
\end{tabular}

Fig. 2. Simple model for guidance during intervention

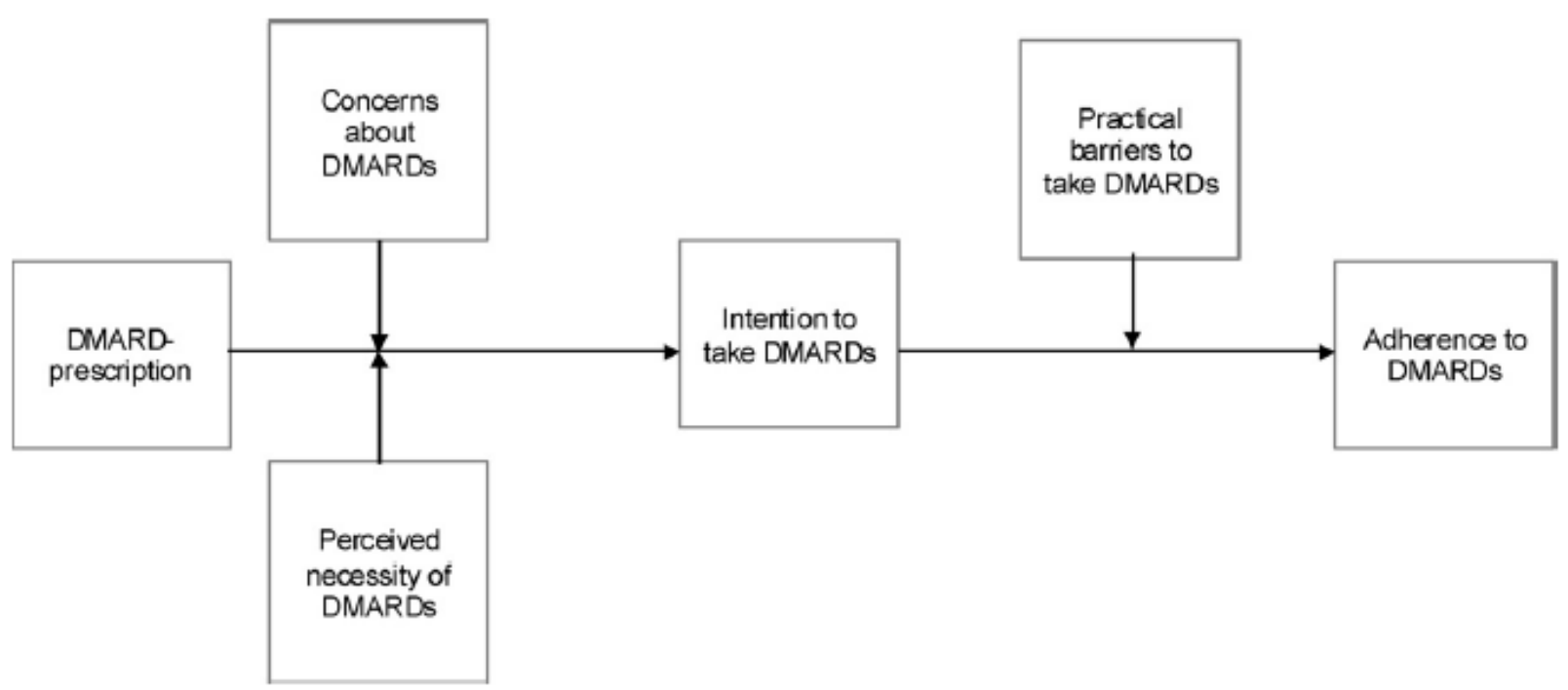


Zwikker, H., Bemt, B. van den, Ende, C. van den, Lankveld, W. van, Broeder, A. den, Hoogen, F. van den, Mosselaar, B. van de, Dulmen, S. van. Development and content of a group-based intervention to improve medication adherence in non-adherent patients with rheumatoid arthritis. Patient Education and Counseling: 2012, 89(1), 143-151

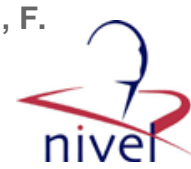

Table 2

Intervention content: function and corresponding determinants, intervention objectives, methods and techniques,

\begin{tabular}{|c|c|c|c|}
\hline Intervention section & Function & $\begin{array}{l}\text { Concerns determinant(s) } \\
\text { and intervention } \\
\text { objectives (see Table 1) }\end{array}$ & Used methods and techniques \\
\hline \multicolumn{4}{|l|}{ First group session } \\
\hline 1.1. Welcome & $\begin{array}{l}\text { Getting to know each other } \\
\text { Understanding intervention } \\
\text { etiquettes, content, context } \\
\text { and aim intervention. Creating } \\
\text { a safe and relaxed atmosphere }\end{array}$ & - & $\begin{array}{l}\text { - Trustworthy messenger } \\
\text { - Use of PowerPoint }\end{array}$ \\
\hline $\begin{array}{l}\text { 1.2. Introduction of } \\
\text { simple behavior } \\
\text { model (Fig. 2) }\end{array}$ & $($ See $\rightarrow)$ & $\begin{array}{l}\text { Knowledge: understanding } \\
\text { that beliefs about medication } \\
\text { and practical barriers contribute } \\
\text { to non-adherent medication } \\
\text { behavior }\end{array}$ & $\begin{array}{l}\text { - Patient education with } \\
\text { imple Behavior model (Fig. 2) } \\
\text { - Use of PowerPoint }\end{array}$ \\
\hline $\begin{array}{l}\text { 1.3. Specification and } \\
\text { personalization of } \\
\text { simple model to } \\
\text { participants, } \\
\text { regarding beliefs } \\
\text { and practical } \\
\text { barriers }\end{array}$ & $\begin{array}{l}\text { Making patients think about } \\
\text { their own necessity and concern } \\
\text { beliefs about medication and } \\
\text { barriers in medication taking } \\
\text { by means of the simple model } \\
\text { (the model was used as } \\
\text { visual tool) }\end{array}$ & $\begin{array}{l}\text { All intervention objectives } \\
\text { except for self efficacy } \\
\text { (see Table 1) }\end{array}$ & $\begin{array}{l}\text { - MI-techniques: expressing } \\
\text { acceptance and affirmation, } \\
\text { giving patients more active } \\
\text { role than intervention leader } \\
\text { - Simple behavior model as } \\
\text { stepping stone } \\
\text { - Personalization of information } \\
\text { - Modeling } \\
\text { - Use of flip-over's (to write } \\
\text { down beliefs/barriers inherent } \\
\text { in the group) }\end{array}$ \\
\hline $\begin{array}{l}\text { 1.4. Explaining and } \\
\text { conducting } \\
\text { homework } \\
\text { assignment }\end{array}$ & $\begin{array}{l}\text { Understanding how assignment } \\
\text { can be conducted, and how it } \\
\text { will be discussed during the } \\
\text { second session (in the homework } \\
\text { assignment, the participants } \\
\text { re-evaluate their own beliefs } \\
\text { and barriers to be well prepared } \\
\text { for second session) }\end{array}$ & $\begin{array}{l}\text { Beliefs about medication } \\
\text { (see Table } 1 \text { ) } \\
\text { Practical barriers } \\
\text { (see Table } 1 \text { ) }\end{array}$ & $\begin{array}{l}\text { - Ml-techniques: giving } \\
\text { patients more active role } \\
\text { than intervention leader, } \\
\text { affirming patient's freedom } \\
\text { of choice and self-determination } \\
\text { (nobody is obliged to decide to } \\
\text { change beliefs or non-adherent } \\
\text { behavior) } \\
\text { - Individual homework } \\
\text { assignment, conducted } \\
\text { with participant workbook } \\
\text { (guides patients in making } \\
\text { re evaluating their own beliefs } \\
\text { and barriers) } \\
\text { - Personalization of information }\end{array}$ \\
\hline $\begin{array}{l}\text { 1.5. Closure of first } \\
\text { session }\end{array}$ & $\begin{array}{l}\text { Sharing of experiences with first } \\
\text { session, receiving 'take home' } \\
\text { message from intervention leader }\end{array}$ & - & - Repeating information \\
\hline \multicolumn{4}{|l|}{ Second group session } \\
\hline 2.1. Welcome & $\begin{array}{l}\text { Reflecting on previous session, } \\
\text { hearing about content second } \\
\text { intervention }\end{array}$ & - & - Repeating information \\
\hline $\begin{array}{l}\text { 2.2. Shortly repeating } \\
\text { simple behavioral } \\
\text { model (see Fig. } 2 \text { ) } \\
\text { and beliefs/barriers }\end{array}$ & $\begin{array}{l}\text { Warming up': memorizing the } \\
\text { behavioral model and the beliefs/ } \\
\text { barriers, inherent in the group in } \\
\text { the first session. Rheumatologist } \\
\text { can use this information in his } \\
\text { presentation (see Section } 2.3 \text { ) }\end{array}$ & $\begin{array}{l}\text { All the intervention } \\
\text { objectives in Table } 1 \\
\text { except for self efficacy }\end{array}$ & $\begin{array}{l}\text { - Repeating information } \\
\text { - Simple behavior model } \\
\text { (see Fig. 2) } \\
\text { - Use of PowerPoint }\end{array}$ \\
\hline $\begin{array}{l}\text { 2.3. Presentation of } \\
\text { rheumatologist and } \\
\text { discussing beliefs/ } \\
\text { barriers, living in } \\
\text { the group }\end{array}$ & $\begin{array}{l}\text { Learning about RA and } \\
\text { medication (use) from a } \\
\text { rheumatologist, comparing } \\
\text { beliefs and barriers as mentioned } \\
\text { in session } 1 \text { with information } \\
\text { of the rheumatologist, asking } \\
\text { questions to rheumatologist }\end{array}$ & $\begin{array}{l}\text { All the intervention goals } \\
\text { in Table } 1 \text { except for self } \\
\text { efficacy }\end{array}$ & $\begin{array}{l}\text { - Ml-techniques: reflective } \\
\text { listening, expressing } \\
\text { acceptance and affirmation } \\
\text { - Repeating information } \\
\text { - Modeling } \\
\text { - Trustworthy messenger } \\
\text { - Use of PowerPoint and } \\
\text { flip-over's of previous session }\end{array}$ \\
\hline $\begin{array}{l}\text { 2.4. Individual input } \\
\text { of patients } \\
\text { regarding } \\
\text { their own beliefs and } \\
\text { barriers }\end{array}$ & $\begin{array}{l}\text { Individual patient tells his/her most } \\
\text { important beliefs about medication } \\
\text { and practical barriers and places } \\
\text { them in the simple behavioral model. } \\
\text { Other participants and intervention } \\
\text { leader provide feedback and solutions }\end{array}$ & $\begin{array}{l}\text { All intervention goals in } \\
\text { Table } 1 \text { except for knowledge }\end{array}$ & $\begin{array}{l}\text { - All mentioned MI-techniques } \\
\text { in Section } 3.3 \\
\text { - Simple behavior model } \\
\text { - Modeling } \\
\text { - Personalization of information } \\
\text { - Individual input of participants } \\
\text { according to homework assignment }\end{array}$ \\
\hline $\begin{array}{l}\text { 2.5. Closure of second } \\
\text { session }\end{array}$ & $\begin{array}{l}\text { Providing suggestions about 'what to } \\
\text { do when medication taking is difficult } \\
\text { in future' (regarding barriers), evaluating } \\
\text { sessions, explaining follow-up call }\end{array}$ & $\begin{array}{l}\text { Practical barriers, self } \\
\text { efficacy (see Table 1) }\end{array}$ & $\begin{array}{l}\text { - All mentioned MI-techniques in Section } 3.2 \\
\text { - Modeling }\end{array}$ \\
\hline
\end{tabular}


Zwikker, H., Bemt, B. van den, Ende, C. van den, Lankveld, W. van, Broeder, A. den, Hoogen, F. van den, Mosselaar, B. van de, Dulmen, S. van. Development and content of a group-based intervention to improve medication adherence in non-adherent patients with rheumatoid arthritis. Patient Education and Counseling: 2012, 89(1), 143-151

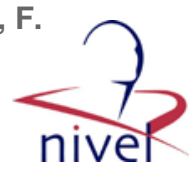

\begin{tabular}{|c|c|c|c|}
\hline Intervention section & Function & $\begin{array}{l}\text { Concerns determinant(s) } \\
\text { and intervention } \\
\text { objectives (see Table 1) }\end{array}$ & Used methods and techniques \\
\hline \multicolumn{4}{|l|}{ Follow-up call } \\
\hline $\begin{array}{l}\text { Follow-up call by } \\
\text { intervention leader }\end{array}$ & $\begin{array}{l}\text { Repeating personal beliefs and barriers } \\
\text { with participant, evaluating effect of } \\
\text { intervention on adherence }\end{array}$ & $\begin{array}{l}\text { Beliefs, practical } \\
\text { barriers (see Table 1) }\end{array}$ & $\begin{array}{l}\text { - Ml-techniques: reflective listening, } \\
\text { expressing acceptance and affirmation, } \\
\text { monitoring readiness for change } \\
\text { (ensuring not jumping ahead of } \\
\text { patient), affirmation patients } \\
\text { freedom of choice regarding } \\
\text { changing beliefs and behavior } \\
\text { - Repeating information } \\
\text { - Personalization of information } \\
\text { - Telephone call to the individual } \\
\text { patient by intervention leader }\end{array}$ \\
\hline
\end{tabular}

Table 3

Intervention materials and their function.

\begin{tabular}{|c|c|}
\hline Material & Function \\
\hline Intervention protocol & Describes intervention background, content and performing 'rules' in detail \\
\hline $\begin{array}{l}\text { Workbook for } \\
\text { intervention leader }\end{array}$ & $\begin{array}{l}\text { Is a shorter and more practical version of the intervention protocol, to guide intervention } \\
\text { leader through the sessions }\end{array}$ \\
\hline $\begin{array}{l}\text { Short guide for } \\
\text { rheumatologist }\end{array}$ & $\begin{array}{l}\text { Gives rheumatologist a quick overview of intervention objectives, so he (or she) can place } \\
\text { his presentation about RA and medicines in the right context }\end{array}$ \\
\hline $\begin{array}{l}\text { PowerPoint } \\
\text { presentations }\end{array}$ & To guide the sessions. There is a presentation for session one, session two and for the rheumatologist \\
\hline Flip-over's & $\begin{array}{l}\text { To guide the sessions (giving participants an overview of beliefs and practical barriers, inherent in } \\
\text { the group) }\end{array}$ \\
\hline $\begin{array}{l}\text { Workbook for } \\
\text { participants }\end{array}$ & 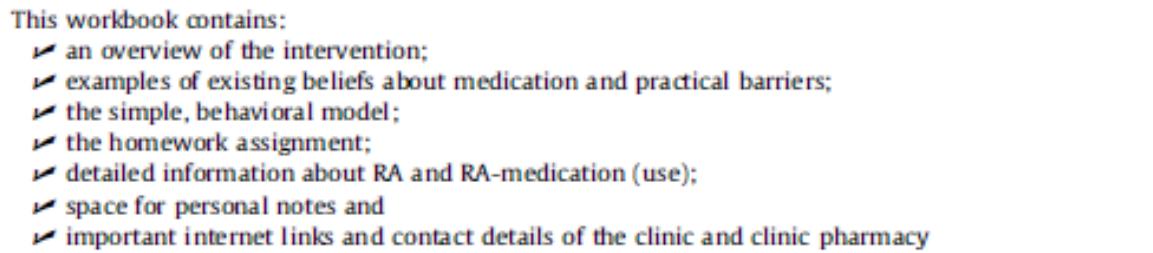 \\
\hline
\end{tabular}

Table 4

Pilot results of patient satisfaction questionnaire $(N=12$, two group sessions piloted twice).

\begin{tabular}{|c|c|}
\hline Item & Median (range) \\
\hline \multicolumn{2}{|l|}{ Satisfaction about general session characteristics } \\
\hline$N$ of sessions too less (0)-too much (6) & $2.5(0-4)$ \\
\hline $\begin{array}{l}\text { Time between sessions ( } 1 \text { week) too short } \\
\text { (0)-too long (6) }\end{array}$ & $3(0-3)$ \\
\hline $\begin{array}{l}\text { Duration of sessions }(1.5 \mathrm{~h}) \text { too short } \\
\text { (0)-too long }(6)\end{array}$ & $3(0-5)$ \\
\hline Group size too small (0)-too big (6) & $3(3-4)$ \\
\hline \multicolumn{2}{|l|}{ Transparency of provided information } \\
\hline $\begin{array}{l}\text { Participant workbook, hard to understand } \\
\text { (0)-easy to understand (6) }\end{array}$ & $5(2-6)$ \\
\hline $\begin{array}{l}\text { Information provided by intervention leader } \\
\text { (pharmacist) unclear }(0) \text {-clear (6) }\end{array}$ & $6(3-6)$ \\
\hline $\begin{array}{l}\text { Information provided by theumatologist unclear } \\
\text { (0)-clear (6) }\end{array}$ & $6(4-6)$ \\
\hline \multicolumn{2}{|l|}{ Communication style characteristics } \\
\hline $\begin{array}{l}\text { 'Enough opportunity to discuss my own } \\
\text { experiences and problems with medication', } \\
\text { totally disagree ( } 0 \text {-totally agree ( } 6 \text { ) } \\
\text { Intervention leader }\end{array}$ & $5(1-6)$ \\
\hline Not stimulating (0)-very stimulating (6) & $5(3-6)$ \\
\hline $\begin{array}{l}\text { Not listening well to participants (0)-listening } \\
\text { well to participants (6) }\end{array}$ & $6(3-6)$ \\
\hline $\begin{array}{l}\text { General atmosphere during the sessions very } \\
\text { tensed }(0) \text {-very relaxed (6) }\end{array}$ & $6(5-6)$ \\
\hline
\end{tabular}

